\title{
Fabrication and Characterization of Unsaturated Copolyesters Based on Diarylidenecyclohexanone
}

\author{
Momen S. A. Abdelaty \\ Polymer Lap, Chemistry Department, Faculty of Science (Assiut), Al-Azhar University, Assiut, Egypt \\ Email address: \\ abdelatymomen@yahoo.com \\ To cite this article: \\ Momen S. A. Abdelaty. Fabrication and Characterization of Unsaturated Copolyesters Based on Diarylidenecyclohexanone. American \\ Journal of Polymer Science and Technology. Vol. 3, No. 1, 2017, pp. 12-20. doi: 10.11648/j.ajpst.20170301.12
}

Received: March 3, 2017; Accepted: March 19, 2017; Published: April 18, 2017

\begin{abstract}
New series of unsaturated copolyesters based on diarylidenecyclohexanone, were synthesized by the interfacial polycondensation polymerization technique. Aldol condensation reaction in acid media was used for preparation of three kinds of monomers and investigated by FT IR and ${ }^{1} \mathrm{H}$ NMR. The copolymers have been synthetized by the polymerization of 2 , 6-bis (4-hydrxybenzylidene) cyclohexanone I, 2, 6-bis (3-hydroxybezylidene) cyclohexanone II, or 2, 6-bis (4-hydroxy-3methoxybenzylidene) cyclohexanone III with isophthaloyl, terphthaloyl, adipoyl, sebacoyl and azobenzene 4, 4dicaroxyldichloride. The resulting copolyesters were characterized by FT-IR, ${ }^{1} \mathrm{HNMR}$. The intrinsic viscosity of these copolyesters was used for the determination of the molecular weight. The thermal stabilities of the prepared copolyesters were evaluated thermogravimeteric analysis (TGA). Differential thermal analysis (DTA) was used for determination of glass temperatures. X-ray analysis showed that polymers have low degree of crystallinity. The morphological properties of some selected copolyesters were detected by SEM. The dielectric and electrical resistance, capacitance, inductance, demonstrating the insulator behaviour of copolymers.
\end{abstract}

Keywords: Copolyesters, Unsaturated, Synthesis, Characterization, Diarylidenecyclohexanone, Dielectric

\section{Introduction}

Unsaturated polyesters are among the most common polymers used in conjunction with glass fibre reinforcing [1, 2] and widely used as thermosetting resins in various industrial areas [3-5]. They are prepared by polycondensation of diacids and diols using titanium or tin alkoxides as catalysis [6]. The reaction temperature is usually up to $150^{\circ} \mathrm{C}$ $[6,7]$. For this condition many monomers are not suitable for the formation of linear polyesters, due to uncontrollable side reactions and formation of gel [8-10]. Typically linear unsaturated polyesters processed to a relatively low molecular weight then it is dissolved in a monomer such as styrene to form a viscous solution. Crosslinking, occurred usually initiated with free radical initiator, as vinyl copolymerization between the polyester and the solvent as vinyl acetate or methyl methacrylate. Haloganated monomers can use for improving flame-resistance, such as ortho- and para-bromostyrene $[11,12]$. The unsaturation has been commercially synthetized by introducing low cost material like maleic anhydride and fumaric acid in the polymer main chain [13]. If only unsaturated acid and glycol are used, the final product is too highly cross-linked and brittle to be useful. For this reason, copolyesters are normally prepared containing both unsaturated acid and a non-cross-linkable acid [13]. Due to the highly extensive uses of unsaturated polyesters, recycling process has been suggested to solve the problems of waste materials. One recent method involves the alcoholises of waste resin with propylene glycol, followed by re-esterification with additional maleic anhydride [14, 15]. More styrene is then added to the reconstituted polymer for cross-linking. Many studies for fabricated polyesters using biocatalysts and green monomers from renewable resources were introduced, attributed to the eco-friendly products. Furthermore, polymers are biodegradable [16, 17]. Nowadays, many studies were focused on the formation of unsaturated polyester composites and their mechanical properties [18-19]. Others studied the unsaturated polyesters as layered silicate nanocomposites [20]. The ratio of the capacitance of a condenser containing the material to the capacitance under vacuum referred to the dielectric constant of material $(\grave{\varepsilon})$. The capacitance of a condenser measures the extent of charges was stored. One approach has focused on 
studying polymer thin films and their electrical properties with special interest to dielectric behaviour for their important applications as insulation, isolation and microelectronics [21, 22]. Addition of some conducting fillers to improve the magnitude of electrical conductivity of insulating polymers materials have been published in recent articles $[23,24]$. The dielectric constant was measured for a variety of materials like cellulosic, [25] protein, and synthetic fibres [26].

The work presented here outlines the synthesis and characterization of new copolyesters of diarylidenecyclohexanone. A major target for this work was to study the effect of alkyl-cycloalkanone moiety on the thermal stability properties of copolyesters. The crystallinity, solubility, morphologic properties of this new class of copolyesters were also examined. Moreover, the electrical properties have been measured for the solid polymers.

\section{Experimental}

\subsection{Materials}

p - Hydroxybenzaldehde and m- Hydroxybenzaldehde were purchased from Aldrich (Germany). 4 - Hydroxy-3methoxybenzaldehyde (vanillin) from El-Nassr Chemical Company (Egypt). p - Nitrobezoic acid from Merck (Germany). Adipoyl, sebacoyl, isophthaloyl and terphthaloyl chlorides were purchased from Merck (Germany), Cyclohexanone Fluka (Germany). Other chemicals were purchased from Aldrich, Merck, Fluka or BDH companies and purified by standard methods

\subsection{Instrumentations}

The infrared spectra for all solid samples were recorded on IR-470 infrared specrophotometer, Shimadzu; and Pye Unicam SP3-100 spectrophotometer (Japan) using KBr pellet technique. Nuclear Magnetic Resonance spectra for monomers and models were recorded on a Varian EM-390 $(90 \mathrm{MHz})$ spectrometer and GNM-LA (400MHz) (USA) spectrophotometer at room temperature in DMSO or $\mathrm{CDCl} 3$ using TMS as the internal reference. Nuclear Magnetic Resonance spectra for polymers were recorded on a Bruker AVANCE 500 (USA) spectrometer $(500 \mathrm{MHz})$ at room temperature in CF3COOD. The ultra-violet visible spectra were scanned on U. V.-Visible spectrophotometer, Labomed, (USA), Spectro Double Beam 8 Auto cell, U. V D 3200, 190 $1100 \mathrm{~nm}$ in conc. H2SO4 as solvent The solubility of the polymer were examined using $0.02 \mathrm{~g}$ of polymer In $(3-5 \mathrm{ml})$ of solvent at room temperature. The inherent viscosities of the polymer solution $(0.5 \% \mathrm{w} / \mathrm{v})$ in conc. H2SO4 were determined at $30^{\circ} \mathrm{C}$ using an Ubbelohde suspended level viscometer VWR (Germany). X-ray diffract graphs of the polymer were obtained with Philips X-ray Pw 1710 (Japan) diffractometer, using Ni-filtered $\mathrm{CuK} \alpha$ radiation. Thermogravimetric analysis (TGA), differential thermal analysis they are carried out in air with Shimadzu TGA-50 and DTA-50 (Japan), thermal analyzer at heating rate of $10^{\circ} \mathrm{C} / \mathrm{min}$. The morphology of the polymer were examined by Scanning Electron Microscopy (SEM) using a JSM-5400 LV instrument; images were recorded with a Pentax Z-50P Camera with Ilford film at an accelerating voltage of $15 \mathrm{KV}$ (USA). Dielectric constant, capacitance, inductance, resistance of polymers were analysed by HIOKI 353250LCR Hi TESTER apparatus 4 (Japan) in the form of disks with $10 \mathrm{~mm}$ diameters and different thickness.

\subsection{Synthesis of Monomers $i$, ii, iii and Their Models ia, iia, iiia}

The monomers I and III and their models were synthesized as described in our previous work [27, 28]. A new monomer II and its model were prepared by the same procedure by condensation of m-hydroxy benzaldehyde with cyclohexanone for $3 \mathrm{hrs}$. as brown needles from ethanol, yield $91 \%$, m. p $215^{\circ} \mathrm{C}$.

Model IIa was obtained by the reaction of 2, 6- bis (3hydroxybenzylidene) cyclohexanone and benzoyl chloride as yellow plates from benzene yield, $93 \%, \mathrm{~m} . \mathrm{p} 216^{\circ} \mathrm{C}$.

${ }^{1} \mathrm{H}$ NMR (90 MHz, DMSO-d6, $\left.\delta\right):=9.75 \mathrm{ppm}(\mathrm{s}, 2 \mathrm{H}$, $2 \mathrm{OH}$ group), at $7.65 \mathrm{ppm}(\mathrm{s}, 2 \mathrm{H}$ of $2 \mathrm{CH}=\mathrm{C})$; at $6.8-7.35$ ppm (m, 8H of $\mathrm{Ar}-\mathrm{H})$, at $2.85 \mathrm{ppm}(\mathrm{m}, 4 \mathrm{H}$ of $2 \mathrm{CH} 2)$ and at 1.85 (pented, $2 \mathrm{H}$ of $\mathrm{CH} \neg 2$ of cyclohexanone).

IR (KBr) (II monomer): $v=$ IR spectra recorded from $\mathrm{KBr}$ pellets showed characteristic bands for $\mathrm{C}=\mathrm{O}$ cyclohexanone at $1690-1700 \mathrm{~cm}^{-1} ; \mathrm{C}=\mathrm{C}$ stretching at $1590-1600 \mathrm{~cm}^{-1}$; phenylene rings at $1590-1510 \mathrm{~cm}^{-1}$.

${ }^{1} \mathrm{H}$ NMR $(90 \mathrm{MHz}, \mathrm{CDCl} 3, \delta): 8.25-8.60 \mathrm{ppm}(\mathrm{m}, 4 \mathrm{H} 30$, $34,35,39$ Ar-H), 7.50 - 8.10 ppm (m, 12H 14-19, 31-33, 3638 Ar-H), $7.15-7.25$ ppm (s, 2H, 8, 9- $\mathrm{CH}=\mathrm{C}), 2.60-2.90$ ppm (t, 4H, 2, 4- 2CH2), 1.25 - 1.85 ppm (pent., 2H 3-CH2) of cyclohexanone.

IR (KBr) (IIa model): $v=1735(\mathrm{~s})(\mathrm{C}=\mathrm{O}$ of ester group), $1670(\mathrm{~s})(\mathrm{C}=\mathrm{O}$ of cyclohexanone), $1600(\mathrm{~s})(\mathrm{C}=\mathrm{C})$.

\subsection{Synthesis of 4, 4-Azodibenzoyldichloride}

This has been done in two steps the first is the formation of azobenzene 4, 4-dicaroxylic acid followed by conversion to acid chloride azobenzene 4, 4-dicaroxylchloride as described previously [29, 30].

\subsection{Synthesis of Copolymers}

In a three necked, round - bottomed flask (500 $\mathrm{cm} 3$ volume) equipped with a mechanical stirrer $(2000 \mathrm{rpm} / \mathrm{min})$, dry nitrogen inlet and out let, and dropper, a mixture of two different monomers ( $\mathrm{mol} / \mathrm{mol})$ of diarylidenecyclohexanone, and a suitable quantity of sodium hydroxide; that is stoichiometric quantity $(0.02 \mathrm{~mol})$ of $100 \%$ excess $(0.04 \mathrm{~mol})$ dissolved in 100 $\mathrm{ml}$ of water was introduced. After mixing $(0.02 \mathrm{~mol}$.) of acid chloride dissolved in $40 \mathrm{ml}$ methylene chloride was added over a period 2-3 min. at $25^{\circ} \mathrm{C}$ and vigorously stirring. After complete addition of acid chloride, the stirring was continued for $60 \mathrm{~min}$., during which yellow solid product separated out. The solid polymer was filtered off, washed by water, hot ethanol, hot acetone, and dried under reduced pressure $(1 \mathrm{mmHg})$ at $100^{\circ} \mathrm{C}$ 
for two days. Three copolyesters series were separated and casted from methylene chloride.

Copolyesters of series IV were prepared by copolymerization of monomers 2, 6-bis (4hydroxybenzylidene) cyclohexanone I, 2, 6-bis (3hydroxybenzylidene) cyclohexanone II, series V monomers 2, 6-bis (4-hydrxybenzylidene) cyclohexanone I, 2, 6-bis (4hydroxy-3-methoxybenzylidene) cyclohexanone III, and series VI 2, 6-bis (3-hydroxybezylidene) cyclohexanone II 2, 6-bis (4-hydroxy-3-methoxybenzylidene) cyclohexanone III, with acid chlorides IVa (isphthaloyl chloride), IVb (terphthaloyl chloride), IVc (adipoyl chloride), IVd (sebacoyl chloride) and IVe (azobenzene 4, 4-dicaroxylchloride) as shown in Table1.

Table 1. Mole ratios of monomers, acid chlorides, physical states, yield\%, viscosity average molecular weight and glass temperature of synthetic copolyesters series $I V$, $V$ and VI.

\begin{tabular}{|c|c|c|c|c|}
\hline Code & $\begin{array}{l}\text { Acid chloride }(0.04 \mathrm{~mol}) \text { in } \\
100 \mathrm{ml} \text { dry } \mathrm{CH}_{2} \mathrm{Cl}_{2}\end{array}$ & $\begin{array}{l}\text { Yield } \\
{[\%]}\end{array}$ & $\begin{array}{l}\text { Mv 10 } \\
\text { g/mol }\end{array}$ & $\mathbf{T}_{\mathrm{g}}\left[^{0} \mathrm{C}\right]$ \\
\hline \multicolumn{5}{|c|}{ Series IV } \\
\hline IVa & $4.02 \mathrm{~g}$ & 93 & 9.00 & 70 \\
\hline $\mathrm{IVb}$ & $4.02 \mathrm{~g}$ & 91 & 8.78 & 78 \\
\hline IVc & $3.66 \mathrm{~g}$ & 87 & 8.45 & 55 \\
\hline IVd & $4.76 \mathrm{~g}$ & 82 & 10.75 & 67 \\
\hline IVe & $6.14 \mathrm{~g}$ & 83 & 7.43 & 95 \\
\hline \multicolumn{5}{|c|}{ Series V } \\
\hline $\mathrm{Va}$ & $4.02 \mathrm{~g}$ & 88 & 6.89 & 65 \\
\hline
\end{tabular}

\begin{tabular}{lllll}
\hline Code & $\begin{array}{l}\text { Acid chloride } \mathbf{( 0 . 0 4 m o l )} \text { in } \\
\mathbf{1 0 0 m l ~ d r y ~} \mathbf{C H}_{\mathbf{2}} \mathbf{C l}_{\mathbf{2}}\end{array}$ & $\begin{array}{l}\text { Yield } \\
{[\mathbf{\%}]}\end{array}$ & $\begin{array}{l}\mathbf{M v} \mathbf{1 0}^{\mathbf{3}} \\
\mathbf{g} / \mathbf{m o l}\end{array}$ & $\mathbf{T}_{\mathbf{g}}\left[{ }^{\mathbf{0}} \mathbf{C}\right]$ \\
\hline $\mathrm{Vb}$ & $4.02 \mathrm{~g}$ & 91 & 8.93 & 82 \\
$\mathrm{Vc}$ & $3.66 \mathrm{~g}$ & 85 & 9.38 & 77 \\
$\mathrm{Vd}$ & $4.76 \mathrm{~g}$ & 94 & 9.77 & 80 \\
$\mathrm{Ve}$ & $6.14 \mathrm{~g}$ & 83 & 6.55 & 105 \\
$\mathrm{Series}$ & & & & \\
$\mathrm{VI}$ & $4.02 \mathrm{~g}$ & 94 & 9.73 & 88 \\
$\mathrm{VIb}$ & $4.02 \mathrm{~g}$ & 90 & 7.45 & 93 \\
$\mathrm{VIc}$ & $3.66 \mathrm{~g}$ & 92 & 7.75 & 85 \\
$\mathrm{VId}$ & $4.76 \mathrm{~g}$ & 89 & 8.32 & 86 \\
$\mathrm{VIe}$ & $6.14 \mathrm{~g}$ & 87 & 6.23 & 115 \\
\hline
\end{tabular}

\section{Results and Discussion}

Here, in this study we used new monomers based on 3hydroxybenzaldehyde for the formation of 2, 6-bis (3hydroxybezylidene) cyclohexanone II by the reaction condition as described in Scheme 1. Further, the model compound was also synthetized and both were characterized by IR and ${ }^{1} \mathrm{HNMR}$.

The new copolyester series containing diarylidenecyclohexanone moiety in the main chain were synthesized by interfacial condensation polymerization technique for one mole of both monomers and two moles of acid chloride as described in scheme 1 . The same technique was used to synthesize a series of polyesters and copolyesters of diarylidenecyclopentanone [31].
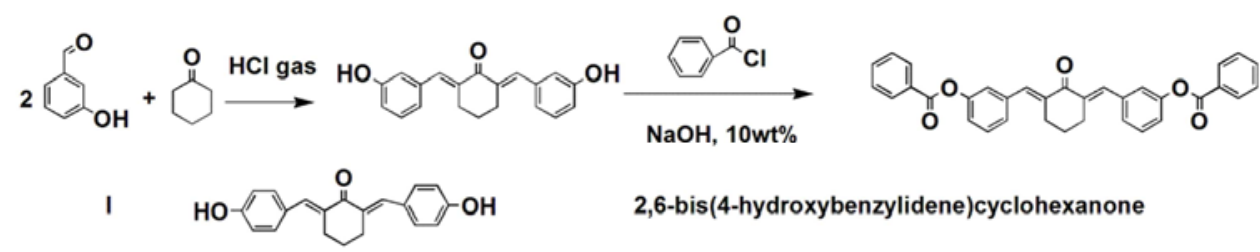

2,6-bis(4-hydroxybenzylidene)cyclohexanone

II

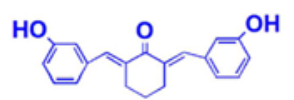

2,6-bis(3-hydroxybenzylidene)cyclohexanone



2,6-bis(4-hydroxy-3-methoxybenzylidene)cyclohexanone
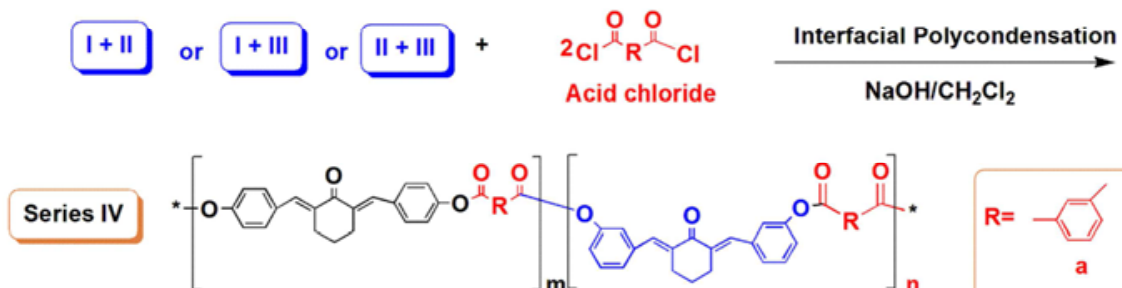

$\mathbf{R}=$

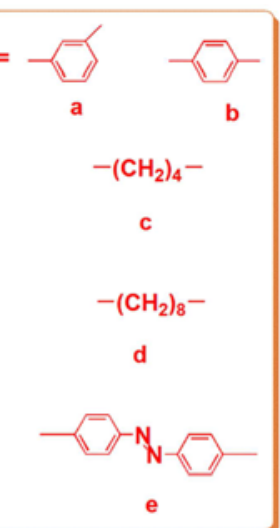

Scheme 1. Synthesis of 2, 6-bis (3-hydroxybezylidene cyclohexanone) II, its model compound and copolyesters of series IV, V and VI. 


\subsection{Polymer Characterizations}

IR spectra: IR spectra recorded from $\mathrm{KBr}$ pellets was mixed with respective polymer showed characteristic bands for $\mathrm{C}=\mathrm{O}$ ester at $1730-1745 \mathrm{~cm}^{-1} ; \mathrm{C}=\mathrm{O}$ cyclohexanone at $1690-1700 \mathrm{~cm}^{-1 ;} \quad \mathrm{C}=\mathrm{C}$ stretching at $1590-1600 \mathrm{~cm}^{-1}$; phenylene rings at $1590-1510 \mathrm{~cm}^{-1}$; and C-O-C bonds (ether linkage) at $1250-1260 \mathrm{~cm}^{-1}$.

\subsection{1. ${ }^{1} \mathrm{H}$ NMR Spectra}

${ }^{1} \mathrm{H}-\mathrm{NMR}$ spectra were recorded using a BRUKER DRX-
500 spectrometer. ${ }^{1} \mathrm{H}-\mathrm{NMR}$ spectra were measured at $25^{\circ} \mathrm{C}$ in $\mathrm{CF}_{3} \mathrm{COOD}$ as an internal reference. The chemical shifts (in ppm) are referenced to tetramethylsilane Figure 1, shows the ${ }^{1} \mathrm{HNMR}$ for selective copolymers (Va, Vd, Ve, VIa, VIb, VIe) all spectra recorded the presence of: $0.90-1.05,1.30-1.65$, 3.00-3.50 ppm (m- $\mathrm{CH}_{2}$-cyclohexanone), 4.00-4.30 ppm (m$\left.\mathrm{OCH}_{3}\right)$, and 7.00-8.90 (m-Ar-H). Moreover, polymer Vd with sebacate main chain showed at 2.5-2.90 ppm $\left(\mathrm{m}-\mathrm{CH}_{2}\right)$.

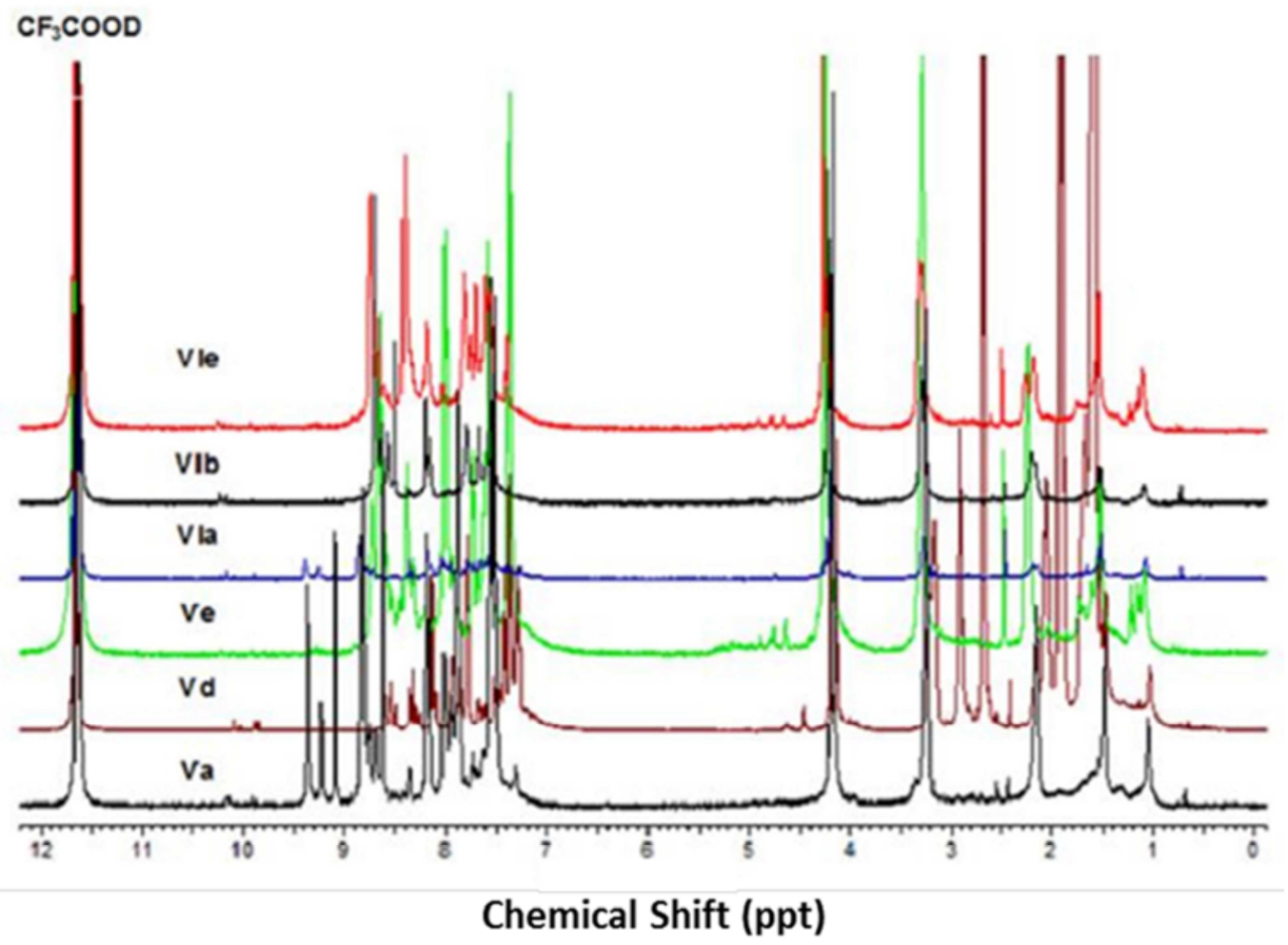

Figure 1. ${ }^{1} \mathrm{HNMR}\left(\mathrm{CF}_{3} \mathrm{COOD}\right)$ of copolyester.

\subsubsection{Solubility}

The solubility of the polymers were tested in various solvents including N-methyl-2- pyrrolidone (NMP), dimethyl formamide (DMF), m-cresol, dimethylsulphoxide (DMSO), $\mathrm{CHCl}_{3}$-acetone mixture, dichloroacetic acid (DCA), and concentrated $\mathrm{H}_{2} \mathrm{SO}_{4}$. It was found from Table 2, that the majority of the polymers were completely insoluble in NMP, $\mathrm{m}$ - cresol, $\mathrm{CHCl}_{3}$-acetone mixture. In strong protic solvents as (DCA) $\left(\mathrm{Cl}_{2} \mathrm{CHCOOH}\right)$ or $(\mathrm{TFA})\left(\mathrm{F}_{3} \mathrm{CCOOH}\right)$ the polymers are completely soluble at room temperature. In case of (conc. $\mathrm{H}_{2} \mathrm{SO}_{4}$ ) all polymers are completely soluble at room temperature. The slightly higher solubility of polymers based on the aliphatic chain in DMSO and DMF in comparison with polymers have aromatic chains in which the presence of aliphatic chains with four or eight methylene groups in the position of rigid benzene caused a small increasing in the solubility in the former polymers than the later polymers.

Table 2. Solubility characteristics of copolyesters series IV, V and VI.

\begin{tabular}{|c|c|c|c|c|c|c|c|c|}
\hline Polymer Code & $\mathbf{A}$ & B & $\mathbf{C}$ & D & $\mathbf{E}$ & $\mathbf{F}$ & G & $\mathbf{H}$ \\
\hline \multicolumn{9}{|l|}{ Series IV } \\
\hline IVa & - & - & - & - & - & + & + & + \\
\hline $\mathrm{IVb}$ & - & - & - & - & - & + & + & + \\
\hline IVc & \pm & \pm & - & - & - & + & + & + \\
\hline IVd & \pm & \pm & - & - & - & + & + & + \\
\hline IVe & \pm & \pm & - & - & - & + & + & + \\
\hline \multicolumn{9}{|l|}{ Series V } \\
\hline $\mathrm{Vb}$ & - & - & - & - & - & + & + & + \\
\hline $\mathrm{Vc}$ & \pm & \pm & - & - & - & + & + & + \\
\hline
\end{tabular}




\begin{tabular}{|c|c|c|c|c|c|c|c|c|}
\hline Polymer Code & $\mathbf{A}$ & B & C & D & $\mathbf{E}$ & $\mathbf{F}$ & G & $\mathrm{H}$ \\
\hline $\mathrm{Vd}$ & \pm & \pm & - & - & - & + & + & + \\
\hline $\mathrm{Ve}$ & \pm & \pm & - & - & - & + & + & + \\
\hline \multicolumn{9}{|l|}{ Series VI } \\
\hline VIa & - & - & - & - & - & + & + & + \\
\hline VIb & - & - & - & - & - & + & + & + \\
\hline VIc & \pm & \pm & - & - & - & + & + & + \\
\hline VId & \pm & \pm & - & - & - & + & + & + \\
\hline VIe & \pm & \pm & - & - & - & + & + & + \\
\hline
\end{tabular}

A (DMF), B (DMSO), C (NMP), D (m-cresol), E (Chloroform: acetone 1: 1),

F (DCA), G (TFA), H (Conc. H2SO4). (+) Soluble at room temperature (RT);

$( \pm)$ partially soluble at RT; (-) insoluble at RT.

\subsubsection{The Viscosity Average Molecular Weight (Mv)}

Polymers under measurement and standards were dissolved in trifluroacetic acid as solvent. The viscosity average molecular weights of polymers were determined according to MarkHounwink equation [32-33] as shown in Table 1.

\subsubsection{Thermal Analysis}

The thermal stabilities of selected examples of copolyesters were evaluated by thermogravimeteric analysis (TGA), Differential thermal analysis (DTA) in air at a heating rate of $10^{\circ} \mathrm{C} \mathrm{min}^{-1}$.

\subsubsection{Thermogravimetric Analysis (TGA)}

TGA curves of all polymers showed similar patterns of decomposition. The temperature for $10 \%$ weight loss is considered to the polymer decomposition (PDT), temperature ranges between $280-370^{\circ} \mathrm{C}$. It should be noted from Figure $2 \mathrm{~A}$ that copolyester that contain aliphatic group in the main chain are thermally less stable than the other with aromatic groups in the main chain. It should be noted that the presence of methoxy groups in the main chain increase the thermal stabilities.

It is clear that copolyesters with azo group as shown in Figure 2B underwent decomposition in two stages. The first stage in the thermal decomposition of these polymers may be the elimination of azo group, probably as molecular nitrogen. Back and Black [34], reported that the first step in the thermal decomposition of certain aromatic polymers prepared by oxidative coupling of primary amines occurs in loss of nitrogen.



(A)

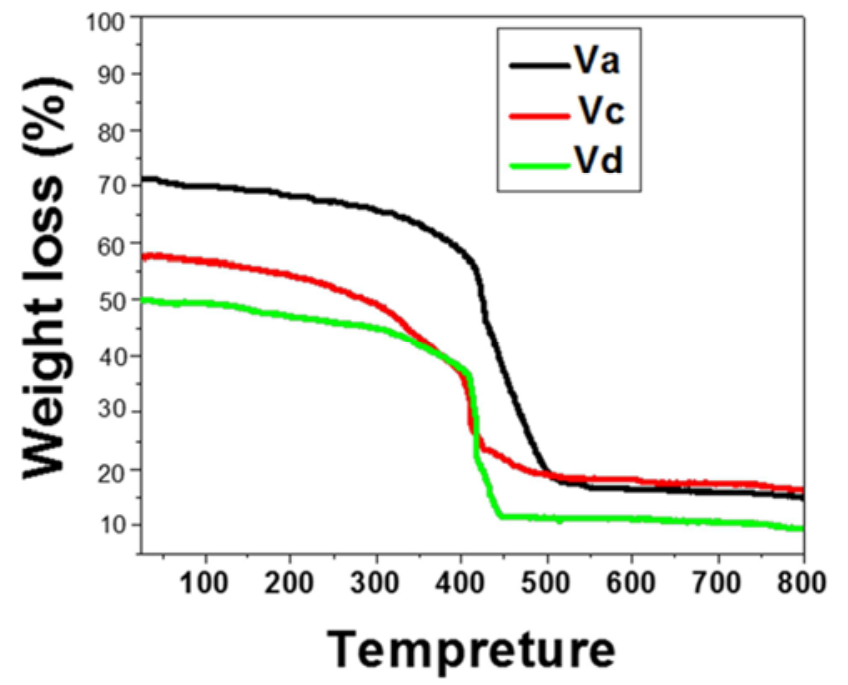

(B)

Figure 2. A, B TGA of copolyesters.

\subsubsection{Differential Thermal Analysis (DTA)}

The selected examples of copolyesters were examined by DTA measurements as shown in Figure 3. The values of $T_{g}$ were summarized in Table 1. From the DTA curves it is easy to determine the glass transition temperature $T_{g}$ of these copolyesters. It should be noted that polymers with rigid chains would be expected to have $T_{g}$ higher than those with flexible molecules. This is because, on melting, polymers with stiff backbones have lower conformational entropy changes than those with flexible backbones. The chain flexibility is enhanced by the presence of - (COO) - and by increasing the length of - $\left(\mathrm{CH}_{2}\right)$ - units in the main. The chain rigidity is enhanced by the presence of aromatic groups in the main chains [34].

It should be noted that $T_{g} s$ for copolyesters with azo groups have higher values than copolyesters others. The interpretation, attributed to the presence of azo groups in the copolyester main chain, causes high hindrances to internal rotation about primary valance bonds, and hence raises $T_{g}$ [35]. The higher $T_{g} s$ values of copolyesters Ve and VIe than IVe, attributed to the presence of methoxy groups as aside groups, which increase the intermolecular bonding in copolyester chain, will significantly increase $\mathrm{T}_{g}[35]$. 

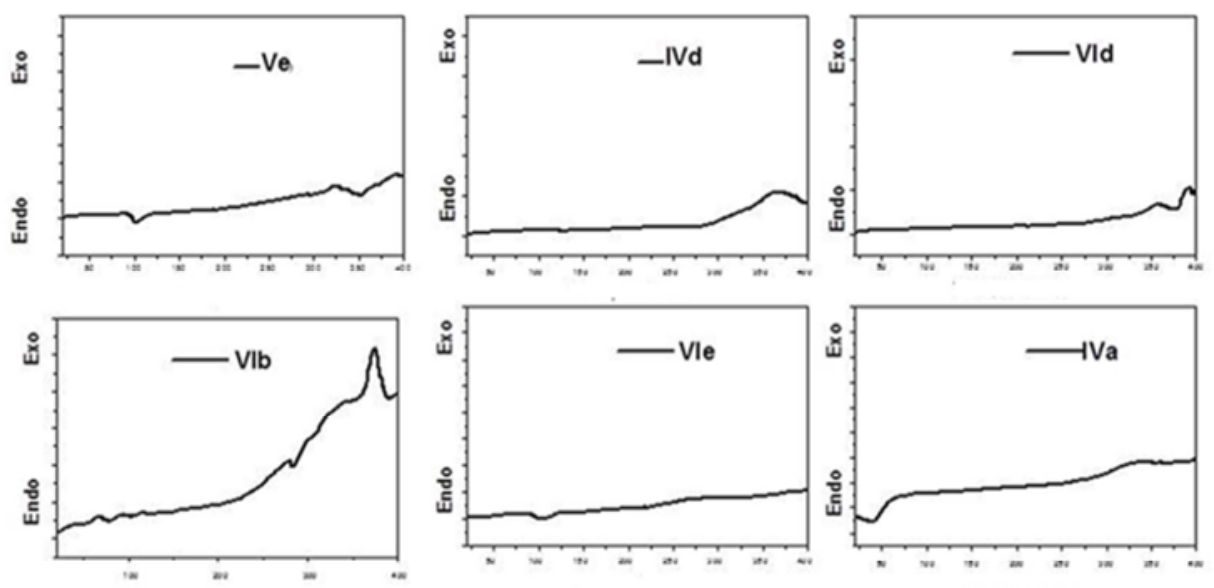

\section{Temperature $\left({ }^{\circ} \mathrm{C}\right)$}

Figure 3. DTA of copolyesters.

\subsubsection{X-Ray Analysis}

X-ray diffractograms of selected examples of copolyesters showed an amorphous patterns in the region $2 \theta=5-30^{\circ}$, after this region showed a few reflections of sharpness peaks with an amorphous back ground in the region $2 \theta=30-60^{\circ}$, this indicate some degree of polycrystallinity of the polymer. It was noted from the Figure 4 that the presence of cyclohexyl ring in the polymer chain beside the presence of methylene groups, four or eight, increase the polymer chain flexibility, that urge the approach and mutual attraction of the adjacent chains might be induced some extent of crystallinity. Moreover, it should be noted that the presence of methoxyl groups as substituent in the phenyl ring caused some hindering between the repeating units and inforced its to the unsymmetrical orienation in the polymer chains and reduced the close packed structure and hence these copolyesters exhibit only a low degree of crystallinity [30]. Moreover, in copolyesters (IVe, Ve, Vie) the presence of $-\mathrm{N}=\mathrm{N}$ - as a polar group in addition to $-\mathrm{C}=\mathrm{C}$ - bonds induces some order between two adjacent chains in the polymer towards some extent of crystallinity [36-37] as shown in Figure4.

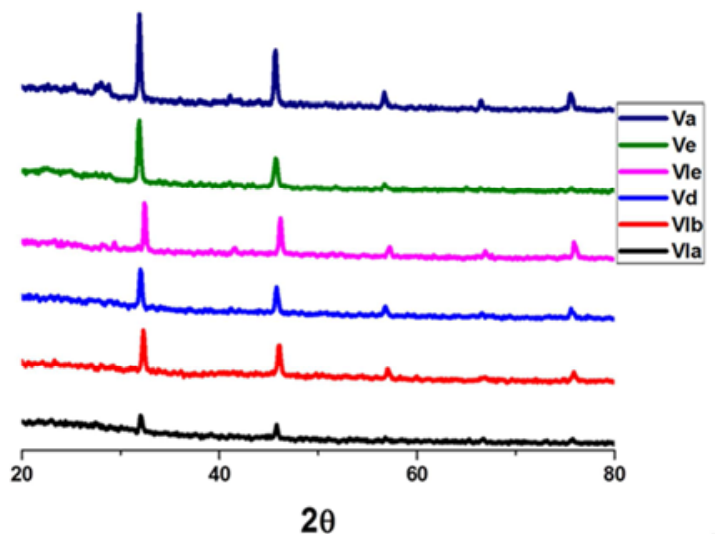

Figure 4. X-ray diffraction patterns of copolyesters $V(a, d, e)$ and $V I(a, b, e)$.

\subsubsection{Morphological Features}

The morphology of the synthesized copolyesters was examined by scanning electron microscopy (SEM). The SEM samples were prepared by putting a smooth part of polymer on a copper holder and subsequently coating it with gold palladium alloy. SEM images were taken on a penta Z Z50 P Camera with Ilford film at an accelerating voltage of $15 \mathrm{kV}$ using a low-dose technique [30, 37]. The study of selected examples of copolyesters showed that the surface of copolyester IVa in Figure 5, magnification of $X=750$ likes scapolite shape which appear as fibrous aggregates. In Figure 6 , magnification of $\mathrm{X}=5000$, showed granoblastic, mosaictype, which likes quartzite rock. In Figure 7, magnification of $X=1500$ likes coral shape. In Figure 8, high magnification of $\mathrm{X}=750$.

Figure 9 magnification of $\mathrm{X}=350$ showed fibrous aggregates, like scapolite group. In Figure 10 magnification of $X=150$; ; appear as granular and compact waxy-looking masses which likes gypstum.

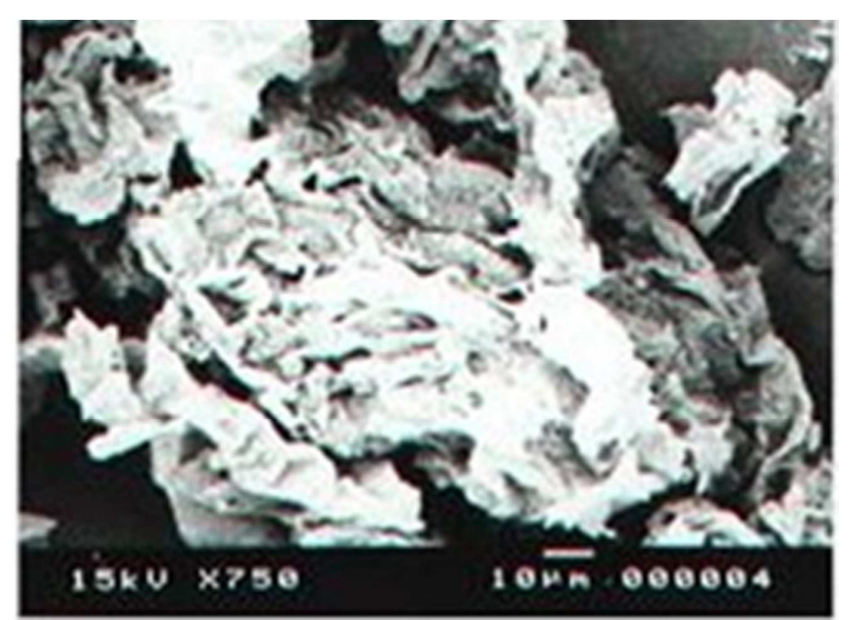

Figures 5. SEM images of copolyesters IVa surface at 750nm magnifications. 


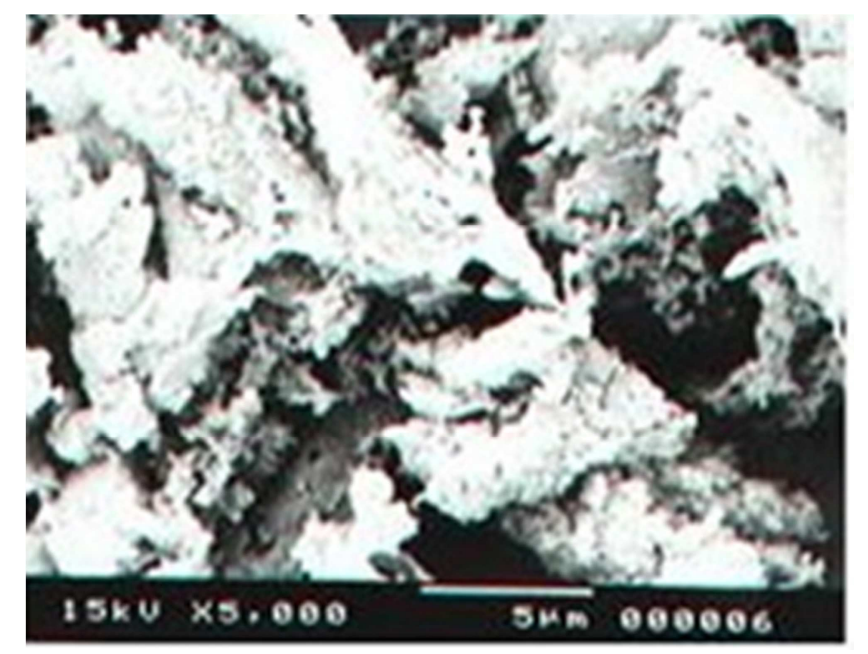

Figures 6. SEM images of copolyesters, IVd, surface at $5000 \mathrm{~nm}$ magnifications.

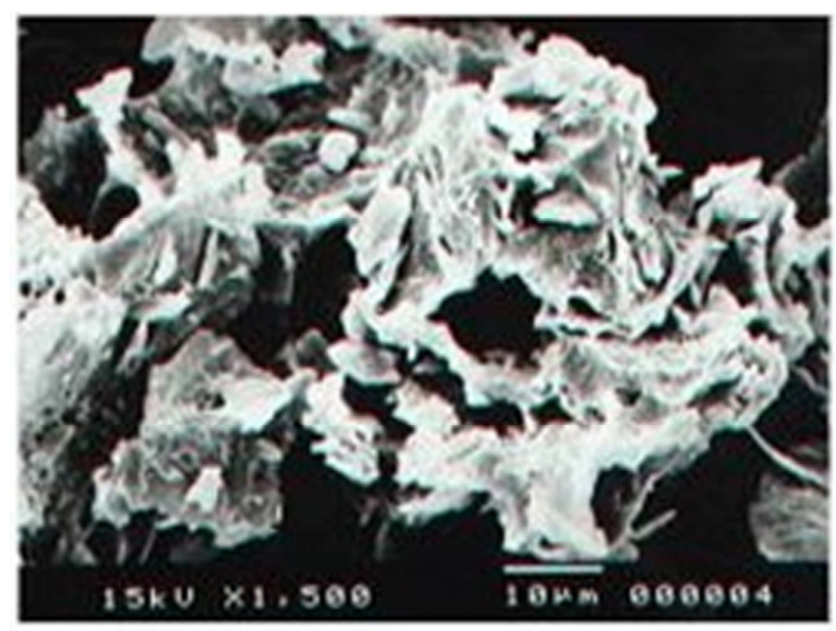

Figures 7. SEM images of copolyesters VIc, surface at $1500 \mathrm{~nm}$ magnifications.

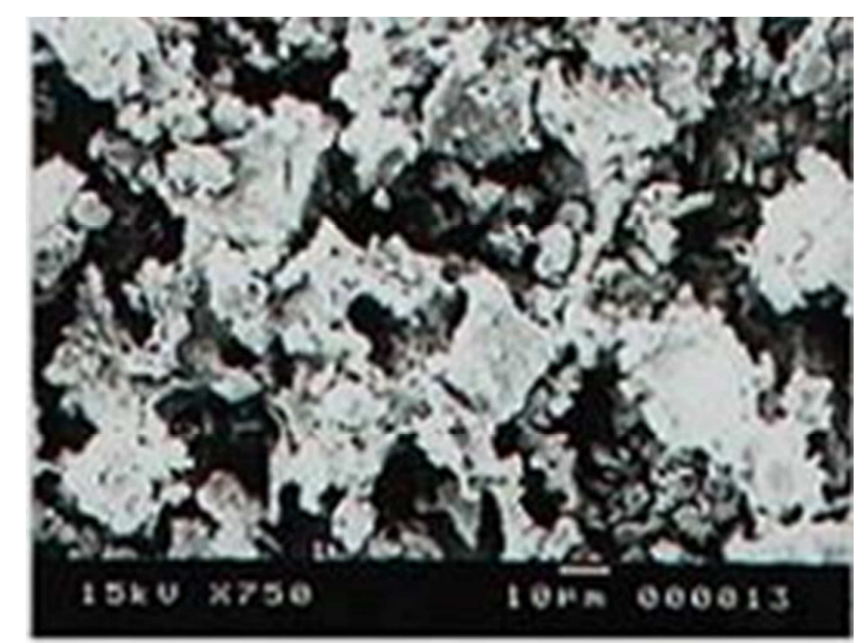

Figures 8. SEM images of copolyesters, Va, surface at $750 \mathrm{~nm}$ magnifications.

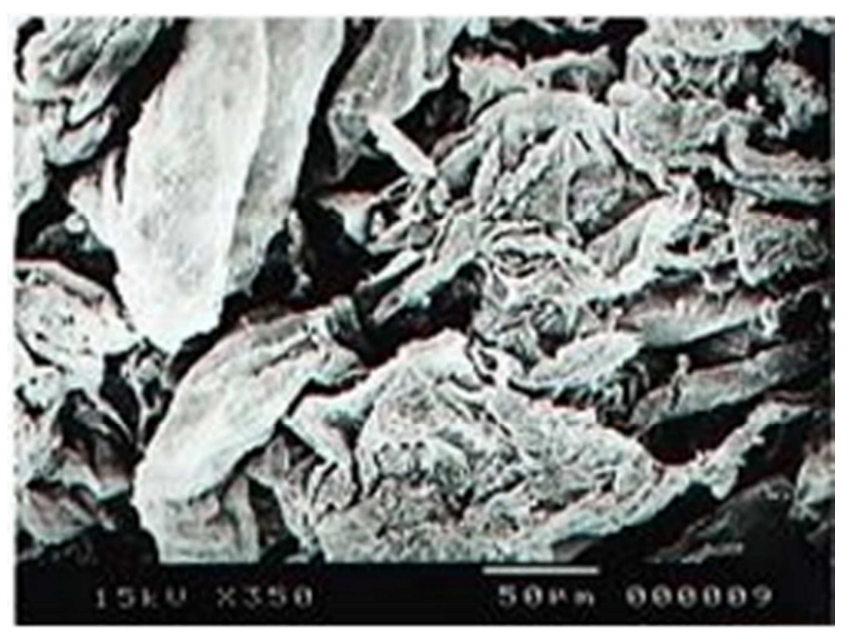

Figures 9. SEM images of copolyesters Vd, surface at 350nm magnifications.

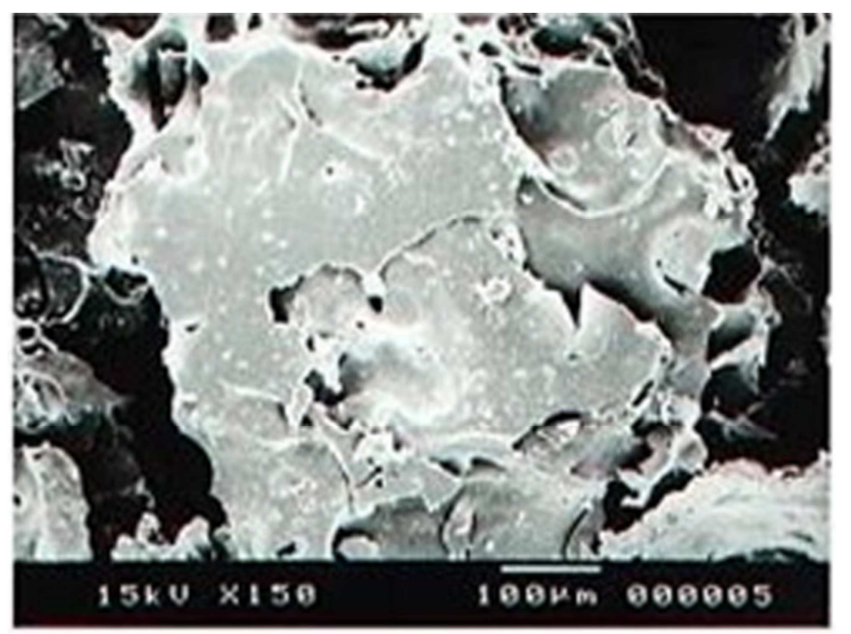

Figures 10. SEM images of copolyesters IVe surface at 150nm magnifications.

\section{Conclusion}

Here we synthetized new aliphatic and aromatic copolysters by interfacial condensation polymerization technique. The solubility of polymers was very poor in organic and inorganic solvent except in very strong acids such as sulphuric and triflouroacetic acids. XRD results showed amorphous case with respect to some semi-crystalline with aromatic and azo copolyesters. Thermogravimetric analyses indicate one and two steps of decompositions. The glass temperature was determined by DTA showed increasing with aromatic and azo copolyesters. The heterogeneous surface with the formation of layers has shown by SEM images.

\section{References}

[1] HV. Boeing, "Unsaturated Polyesters: Structure and Properties", Elsevier Publishing Company, Amsterdam, London, New York, 1964.

[2] B. Parkyn, F. Lamb, BV. "Clitton, "unsaturated polyesters and polyesters plasticizers". Elsevier, New York, polyesters, 1976. 
[3] N. Teramoto, M. Ozeki, I. Fujiwara, M. Shibata, "Crosslinking and biodegradation of poly (butylene succinate) prepolymers containing itaconic or maleic acid units in the main chain”, J Appl Polym Sci, (95), pp.1473-1480, 2005.

[4] DG. Barrett, TJ. Merkel, JC. Luft, MN. Yousaf, "One-step syntheses of photo-curable polyesters based on a renewable resource", Macromolecules (43), pp. 9660-9667, 2010.

[5] L. Jasinska, CE. Koning, "Unsaturated, biobased polyesters and their cross-linking via radical copolymerization", J Polym Sci Pol Chem, (48), pp. 2885-2895, 2010.

[6] Y R. Zhang, S. Spinella, W. Xie, J. Cai, Y. Yang, YZ. Wang, RA. Gross, "Polymeric triglyceride analogs prepared by enzyme-catalyzed condensation polymerization. Eur Polym J (49), pp. 793-803, 2013.

[7] RA. Gross, M. Ganesh, W. Lu, "Enzyme-catalysis breathes new life into polyester condensation polymerizations", Trends Biotechnol, (28), pp.435-443, 2010.

[8] Y. Jiang, W. Albert, K. Alberda, L. Katja, Enzyme-catalyzed synthesis of unsaturated aliphatic polyesters based on green monomers from renewable resources. Biomolecules, (3), pp. 461-480, 2013.

[9] A. Mahapatro, B. Kalra, A. Kumar, RA. Gross, “ Lipasecatalyzed polycondensations: Effect of substrates and solvent on chain formation, dispersity, and end-group structure", Biomacromolecules, (4), pp. 544-551, 2003.

[10] N. Marioara, "Aromatic polyesters with photosensitive side chains: Synthesis, characterization and properties", J Serb Chem Soc, (81), pp.1-14, 2016.

[11] D. Alsheh, G. Marom "Bromostyrene crosslinked polyesters. IV. The effects of the $\mathrm{C}-\mathrm{Br}$ bond strength and of synergists on fire retardancy", J Appl polym sci, (22), pp.3177-3184, 1978.

[12] W. Zaifei, WM. Christopher, SB. Frank "Fluorine-enriched melt-blown fibers from polymer blends of poly (butylene terephthalate) and a fluorinated multiblock copolyester", Appl Mater Interfaces, (8), pp.754-761, 2016.

[13] Triviede, BC, Culbertson BM (1982) Maleic anhydride. Plenum Press, New York, Chap. 12.

[14] KH. Yoon, AT. Dibenedetto, S. Huang, "Recycling of unsaturated polyester resin using propylene glycol polymer", J polymer, (38), pp. 2281-2285, 1997.

[15] M. Fouad, R. Abdelkhalek, I. Jalal "New aromatic-aliphatic co-polyesters: Effect of the Structural characteristic on the thermal Properties", J Mater Environ Sci, (6), pp.1377-1385, 2015.

[16] Alessandro P, Enrique HA, Valerio F, Doris R, Georg MG, Lucia G "the Closure of the Cycle: Enzymatic Synthesis and Functionalization of Bio-Based Polyesters", Trends in Biotechnology, (4), pp. 316-328, 2016.

[17] K. Elayaraja, K, Kishor S, M. Giridhar, "Copolyesters from Soybean Oil for Use as Resorbable", Biomaterials. Sustainable Chem. Eng (5), pp. 880-891, 2015.

[18] Liu, F. Wang, T. Tan, B., "Chen Lipase-catalyzed synthesis and characterization of polymers by cyclodextrin as support architecture" Carbohydr Polym, (92), pp. 633-640, 2013.

[19] A S. Moyeenuddin,, L P. Kim, F. Alan "Effect of fibre treatments on interfacial shear strength of hemp fibre reinforced polylactide and unsaturated polyester composites", J Composites: Part A (42), pp. 1189-1196, 2011.

[20] M. A. Motawie, NM. Ahmed, SM. ElMesallamy, EM. Sadak, NG. Kandile, "Unsaturated Polyesters/layered Silicate Nanocomposites: synthesis and Characterization", Journal of Applied Chemistry (IOSR-JAC) (10), pp. 34-43, 2014.

[21] RJ. Sengwa, S. Sankhla "Characterization of ionic conduction and electrode polarization relaxation oligomers", Polymer Bulletin, (60), pp. 689-700, 2008.

[22] L. Yao, W. He, S. Zuosen, M. Jingjing, W. Xuesong, Y. Donghang, C, Zhanchen "Novel high- k polymers as dielectric layers for organic thin- film transistors", Polym Chem (6), 6651-6658, 2015 .

[23] T. Kimura, M. Kajiwara "Electrical properties of poly (nbutylamino) (di-allylamino) phosphazene", Journal of Material Science, (11), pp. 2955-2959, 1998.

[24] S. Shekhar, V. Prasad, SV. Subramanyam, "Structural and electrical properties of composites of polymer-iron carbide nanoparticles embedded in car bon", Materials Science and Engineering B: (133), pp. 108-112, 2006.

[25] GhA. Omed, G M. Jamal, DA. Tahir, SR. Saeed, "Electrical Characterization of Polyester Reinforced by Carbon Black Particles", International Journal of Applied Physics and Mathematics (2), pp. 101-105, 2011.

[26] K. Bal, VK. KothariIndian "Measurement of dielectric properties of textile materials and their applications", Journal of Fibre and Textile Research, (34), pp. 191-199, 2009.

[27] MA. Abd-Alla, MM. Kandeel, I A. Kamal, AS. Hammam, "Arylidene Polymers II. Synthesis and Chatracterization of New Polyesters of Diarylidenecyclopentanone", Journal Macromolecular Science Chemistry A, (27), pp. 523-538, 1990.

[28] M A. Abd-Alla, I A. Kamal "Arylidene Polymers X. Synthesis and Characterization of New Polyesters Containing Symmetrical Bis-Azomethine Groups in the Polymer Backbone", High Performance Polymers, (2), pp.181-188, 1990.

[29] D H. Marrian, P B. Russell, BJF. Hudson, JW. Cornforth, RH Cornforth, WJ. Dunstan, ML. Tomlinson J Chem Soc, (23), pp. 753-756, 1946.

[30] I A. Kamal, AS. Hammam, SM. Radwan, MA. Abdel-Rahman, "New Unsaturated Copolyesters based on Diarylidenecyclopentanone. Optimum conditions of Synthesis, Characterization and Morphology", International Journal of Basic \& Applied Sciences IJBAS-IJENS11 (4), pp. 14-22, 2011.

[31] MA. Abd-Alla, I A. Kamal, AS. Hammam, "Arylidene Polymers IV. Synthesis, characterization and morphology of new polyesters of diarylidenecyclohexanone", High Performance Polymer (3), pp. 223-234, 1989.

[32] HM. Kwaambwa, JW. Good, RW. Hoghes, PA. Raynolds, "Viscosity, molecular weight and concentrations relationships at $298 \mathrm{~K}$ of low molecular weight cis-polyisoprene in a good solvent", Colloid and surfaces A physicochem. Eng Aspects (294), pp. 14-19, 2007.

[33] S. Hina, Y. Zhang, H. Wang "Characterization of polymeric solutions: a brief overview" Rev Adv Mater Sci, (36), pp.165176, 2014. 
[34] M P. Stevens, Polymer Chemistry: An introduction- $3^{\text {th }}$ Edition, Oxford University, New York, 1999.

[35] VS. Prasad, KS. Pillai Synthesis and thermal behavior of thermotropic terpolymers based on 8- (3-hydroxyphenyl) octanoic acid, 2, 6-naphthalenedicarboxylic acid, and substituted hydroquinones. J of applied polymer science (82), pp. 1021-1029, 2001.

[36] MA. Abd-Alla, MF. El-Zohhry, IA. Kamal, MMA. Mohamed,
Arylidene Polymers XVIII. Synthesis and thermal behavior of organometalic Arylidene polymers containing ferrocene derivatives in the main chain. J of Applied Polymer Science (47), pp.323-329, 1993.

[37] R O. Ebewel, B. Raton Polymer Science and Technology (chain flexibility P.111) London New York Washington, D. C, 1996. 